\title{
Kanttekeningen bij het Merkwaardig Verhaal van M.C. Vos
}

\author{
Gerrit J. Schutte \\ VU University Amsterdam \\ Amsterdam, The Netherlands \\ University of South Africa \\ gj.schutte31@gmail.com
}

\begin{abstract}
The Rev M.C. Vos (1759-1825), born at the Cape, clergyman in The Netherlands, at the Cape and Sri Lanka, is known as an initiator of the mission in South Africa. His life is mostly based on his autobiography Merkwaardig verhaal (1824). Some factual historical remarks learn, however, that his autobiography is far from a virtual (auto) biography, it is his story of God's guidance in his life and an incentive to a religious revival.
\end{abstract}

Trefwoorde

M.C.Vos; Piëtisme; sending; autobiografie; kerkgeskiedenis

\section{Keywords}

M.C. Vos; Pietism; mission; autobiography; church history

Michiel Christiaan Vos (Kaapstad 21 december 1759-26 december 1825 Tulbagh) heeft een bekende naam in de Kaapse geschiedenis. Hij was immers als predikant van Roodezand (Tulbagh) (mede)verantwoordelijk voor de "sendingsontwaking van die Kaapse kerk", ${ }^{1}$ eind 18de eeuw; en ook is hij wel "de eerste zwarte schrijver in Zuid-Afrika" genoemd. ${ }^{2}$ Het beeld en de biografie van Vos zijn grotendeels gebaseerd op zijn autobiografie

1 H.D.T.du Toit, "Michiel Christiaan Vos”, SABW II 844-846.

2 S. Huigen, "Michiel Christiaan Vos. De eerste zwarte schrijver in Zuid-Afrika", Tydskrif vir Nederlands en Afrikaans 1997) 203-209. 
Merkwaardig Verhaal, in 1824 in Amsterdam verschenen. ${ }^{3}$ Het lijkt zinvol daar wat vraagtekens bij te stellen.

Serieuze bevindelijke gelovigen vertelden graag van "de wegen en handelingen Gods met hen gehouden". ${ }^{4}$ Ook Vos. Hij had vier oudere broers en zijn vader overleed toen hij vijf was, terwijl zijn moeder spoedig hertrouwde; hij overleefde een aanval van de pokkenziekte in 1768 en had last van huiduitslag, wat hem enigszins beperkte in jongensspel en sommige vermaken, maar hij bleef "gezond van hart", hield van lezen en nadenken, een serieuze jongen, en toen hij wat ouder werd was hij een ijverig bezoeker van conventikels van vromen. De gesprekken daar en geestelijke lectuur deden bij hem het verlangen opkomen dominee te worden. ${ }^{5} \mathrm{Hij}$ had kennelijk goed schoolonderwijs gevolgd, tot zijn veertiende, toen ging hij aan het werk bij zijn oudste broer ${ }^{6}$ als leerling-zilversmid. Een niet opvallende jeugd dus, bijzonder maar niet uniek werd het pas toen hij wilde theologie gaan studeren.

De theoloog H.D.A. du Toit begon echter de kennismaking met M.C. Vos met de woorden: "Van kindsbeen word (Vos) geteister deur kwale wat hom 'n swak gestel en 'n neerslagtige gemoedsgesteldheid besorg. Toe hy vijf jaar oud is, sterf sy vader, waarna sy moeder weer trou. In 1768 word V. as kind ook siek tydens die pokke-epidemie en in 1773 gaan hy in Kaapstad as vakleerling by sy oudste broer werk om silwersmid te word." 7 Het zal zijn bedoeling niet zijn geweest, maar Du Toit beoefende hagiografie:

3 Merkwaardig verhaal aangaande het leven en de lotgevallen van Michiel Christiaan Vos, als predikant der Hervormde Christelijke Gemeente op onderscheidene plaatsen in Nederland, Afrika en Azië; van zijne Jeugd af tot den tijd van zijn Emeritusschap door hem zelven in den Jare 1819 briefsgewijze aan eenen vriend medegedeeld (Amsterdam: A.B. Saakes, 1824). Ik citeer een herdruk: Nieuwe uitgave, van breedvoerige aanteekeningen voorzien door J. du Plessis, Uitgave der Bijbel-en Bid-Vereeniging (Kaapstad, Hollandsch-Afrikaansche Uitgevers Maatschappij v.h. Jacques Dusseau \& Co, 1911); deze herdruk wordt niet genoemd in het "Ten geleide" van de bewerkte uitgave Ik zal u niet verlaten. Leven en werk van Michiel Christiaan Vos (1759-1826) (Houten: Den Hertog 1999).

4 Vos, Merkwaardig Verhaal, vii.

5 Vos, Merkwaardig verhaal, eerste en tweede brief.

6 Jan Hendrik Vos (geboren 23.3.1749) werd "een bekende zilversmid" en was met zijn jongere broer Jacobus Johannes aannemer van het Hospitaal (D. Bax, Het oudste Kaapse zilver 1669-1751 (Amsterdam 1974) 93, 201.

7 Du Toit, "Michiel Christiaan Vos”, 844. 
heiligen en "grote mannen" hebben altijd een ongelukkige jeugd. Vos was niet ongelukkig, maar hij kwam in contact met een opwekkingsbeweging, die de klemtoon legde op de noodzaak van persoonlijk geloven, kennis van eigen zonde en schuld, bekering en toeëigening van het heil. En de opdracht, anderen daar op te wijzen. Hij wil daarom theologie studeren, predikant worden. ${ }^{8}$

Om predikant te worden betekende naar Nederland reizen en daar te gaan studeren. Zijn erfdeel van de nalatenschap van zijn vader berustte echter bij de Weeskamer en zou pas uitgekeerd worden wanneer hij volwassen was, op 25-jarige leeftijd. ${ }^{9}$ Het huwelijk maakt echter volwassen en daarom trouwde Vos op 14 november 1779 als nog net 19-jarige met Elizabeth Johanna Jacobse die hij in de conventikels had ontmoet. ${ }^{10}$ Daarop reisde hij, zonder zijn vrouw, in februari 1780 naar Nederland. ${ }^{11}$ Hij studeerde snel, eerst de noodzakelijke voorkennis (Latijnse school?), dan theologie, en op 7 juni 1784 liet hij zich door de classis Amsterdam examineren, omdat die predikanten voor de Indische (en Kaapse) kerken koos. Hij werd beroepbaar (proponent) gesteld, maar zijn poging, door Bewindhebbers van de VOC aangesteld te worden tot predikant voor Kaapstad, mislukte door "den verregaande tegenstand van dien Amsterdamsche Gedeputeerde" in het classicale Deputaatschap over Indische Zaken, die waarschuwde voor de dweper Vos. ${ }^{12}$ Zo bleef hij "buiten de gelegenheid, om het eigenlijk oogmerk mijner afzondering tot de Evangeliedienst, ten beste

8 Vos, Merwaardig verhaal, brief 2.

9 Zijn vader Jan Hendrik Vos overleed op 28 december 1765; zijn nalatenschap MOOC8/12.11 omvatte een huis en tuinland.

$10 \mathrm{Zij}$ was 23.7.1758 geboren; haar moeder was een dochter van de ziekentrooster Jan van der Trans, die in 1752 opdracht kreeg "de jongeluyden, die onder de diaconie gehooren en niet meer ter schoole gaan, mitsgaders alle onvermogenden, hunne belijdenisse gaan leeren"(C. Spoelstra, Bouwstoffen voor de geschiedenis der Nederduitsch-Gereformeerde kerken in Zuid-Afrika (Amsterdam-Kaapstad 1906-1907, 1936, 3 dln) II, 279 (1752).

11 Resolutie Raad van Politie Kaap de Goede Hoop 10.2.1780: toestemming tot vertrek als passagier per VOC-schip, "in de Cajuit", onder betaling van het gewone transport- en kostgeld.

12 Merkwaardig Verhaal, 51. Dat Vos een leerling was van prof. G.Bonnet in Utrecht, die een Voetiaan was en sympathiek stond over het piëtisme, telde zwaar: de Deputaten en de vigerende predikanten aan de Kaap waren tegen bevindelijkheid en piëtisme, vergelijk de afwijzing van bevindelijke ziekentroosters (Bouwstoffen I, 241) en de passerende predikant H.H. van der Veen (G.J. Schutte,"Over bevindelijke vroomheid in de Kaapkolonie", NGTT 51 (2010) 131-142. 
mijner landgenoten, vooral der arme slaven, te bereiken". ${ }^{13}$ Dus aanvaardde Vos een beroep uit het Utrechtse dorp Woudenberg, en werd er op 3 juli 1785 bevestigd. In augustus 1786 voegde zijn vrouw zich bij hem. ${ }^{14}$ In zijn autobiografie erkende Vos, dertig jaren later, dat de gemeente Woudenberg "een goede oefenschool" voor het predikantschap was, al was hij er "niet geheel bevrijd van hartzeer, dat ik door geestelijken dwang van mijn Land en mijne maagschap terug gehouden werd". ${ }^{15}$

De autobiografie van een bevlogen piëtist is een lastige bron. ${ }^{16}$ Het Merkwaardig verhaal is zeker geen notariële acte of journaal van een boekhouder, en ook geen gedegen biografie. Het is het verhaal van een geestelijke ommekeer, verslag van een redding, een dankwoord en vooral een oproep tot bekering. Het was, om Vos zelf te citeren, de geschiedenis van "de wegen en handelingen Gods met mij"17 en geschreven tot "opwekke[n] tot geloof aan en vertrouwen in Hem". ${ }^{18}$ Vos schreef zijn herinneringen bovendien tijdens zijn emeritaat ${ }^{19}$ en ze waren onmiskenbaar gekleurd door zijn levenslange ervaringen, zijn zelfbeeld van dat moment: een tevreden, bevlogen en veelszins succesrijk en omstreden opwekkingsprediker en zendeling.

Zo "'n voorbeeld van aangepast, gekleurd stukje geschiedenis is de herinnering" van Vos dat hij vanaf het begin theologie studeren en predikant

13 Merkwaardig Verhaal, 62.

14 NHK Woudenberg, Naamlijst der Lidmaten, 22.8.1786 ingekomen "met attestatie van Cabo de goede Hoop Elisabeth Jacobse, Huisvrouw van M.C. Vos V.D.M.”.

15 Merkwaardig Verhaal, 63.

16 Jan Romein, De Biografie ( ) 204: "de autobiografie is de gevaarlijkste van alle bronnen"; L.F. Groenendijk en F.A. van Lieburg, Voor edeler staat geschapen. Levensen sterfbedbeschrijvingen van gereformeerde kinderen en jeugdigen uit de $17 e$ en $19 e$ eeuw (Leiden 1991); F.A. van Lieburg, Levens van vromen. Gereformeerd piëtisme in de achttiende eeuw (Kampen 1991; L.F. Groenendijk, "De spirituele (auto)biografie als bron voor onze kennis van de religieueze opvoeding" in L.F. Groenendijk en J. Sturm, Leren geloven in de Lage Landen. Facetten van geschiedenis van de religieuze opvoeding (Amsterdam 1993) 57-90; F.A. van Lieburg, "De verbale traditie van een pietistische geloofservaring", in Tijdschrift voor Sociale en Economische Geschiedenis 1(2004) 6685; M.H. Huisman, Publieke leven. Autobiografieën op de Nederlandse boekenmarkt 1850-1918 (Rotterdam 2008). Vergelijk ook W. Frijhoff, Wegen van Willem Evertsz. Een Hollands weeskind op zoek naar zichzelf, 1607-1647 (Nijmegen 1995).

17 Merkwaardig verhaal, vii

18 Merkwaardig Verhaal, x.

19 In 18 
worden wilde om aan de Kaap de evangeliedienst te brengen aan "vooral de arme slaven". Dat stelde hij wel in de Inleiding van zijn Merkwaardig Verhaal, maar ik geloof dat niet, die woorden gaven zijn denken van van veertig jaren na dato. Toen hij opgroeide, was de werkelijkheid dat er slaven en slavinnen aan de Kaap werden gekerstend, en die op hun beurt hun kinderen lieten dopen; hetzelfde gold voor de zogenaamde vrijzwarten, vrij geworden mensen met slavenafkomst. Zij kwamen niet tot geloof door een georganiseerde, bewuste evangelisatie- of zendingsactie maar door gelovigen in hun omgeving, medeslaven, soms eigenaren die hun slavenpersoneel stimuleerden tot kerstening. ${ }^{20}$ Maar expliciete kerkelijke evangelisatie/zending onder de Khoikhoi, vrijzwarten en slaven was er niet: er werd wel regelmatig over gesproken maar om allerlei redenen niet gerealiseerd. ${ }^{21}$ Die werd - afgezien de abortieve actie van de Hernhutter zendeling Schmidt rond 1740 - pas werkelijkheid door de stimulansen van Ds. Helperus van Lier (predikant van Kaapstad 1786-1793), de tweede aankomst van Hernhutters in 1792, de komst van de zendelingen van de London Missionary Society in 1799 en diverse persoonlijke activiteiten die in 1799 samengingen in het Zuid-Afrikaanse Zending Genootschap van 1799. ${ }^{22}$ Toen Vos in 1779 stappen nam om predikant te worden, leefde aan de Kaap het nieuwe geloofszendingsbesef niet, en in het binnenland voerden "blanke Christenen" en "zwarte heidenen" een harde oorlog. ${ }^{23}$ Vrome piëtistische vrouwen als Hendrina Cecilia Kruger waren er slachtoffer van en waren druk met hun eigen perrsoonlijk geloof, maar niet bezig met de kerstening van de Khoisan en Xhosa. ${ }^{24}$ Volgens mij wilde Vos predikant

20 Zie bijvoorbeeld G.J. Schutte, Koloniaal Kaapstad in 1751-1752. Brieven van de tantes Ten Damme aan hun nichtjes Swellengrebel (Amsterdam: Zuid-Afrikahuis 2020) 69-81.

21 Vergelijk Bouwstoffen, II 723-724.

22 Karel Schoeman, Dogter van Sion (Kaapstad 1997); Karel Schoeman, The early Mission / Die vroeë sending in Suid-Afrika (Pretoria 2007); Karel Schoeman, Die Bosmans van Drakenstein 1705-1842 (Pretoria 2010).

23 Vergelijk G.J. Schutte ed. Hendrik Swellengrebel in Afrika: Journalen van drie reizen in 1776-1777 (Kaapstad: VRV/VRS, 2018) lvii, 126.

24 Vergelijk A.W.G. Raath, "Petit bourgeoisie, female piety and mystical Pietism on the South African frontier, 1760-1860", Studies Historiae Ecclssiasticae 40 (2014) 95-116; A.W.G. Raath, "Hendrina Cecilia Kruger se godsdienstige mentaliteitsprofiel in haar mistieke oordenkingsbundel (ca.1750-1810)”, HTS Teologiese Studies 71/1 (2015) 10 blz.; zie ook de schrijvende vrouwen Susanna en Elizabeth Bosman, Elizabeth Conradie in Pieta van Beek en Annemarie van Niekerk eds., My mother's mother's mother. South 
worden, en het mooist zou natuurlijk zijn om predikant te worden in eigen regio (er waren ook voorbeelden: de aan de Kaap geboren P. van der Spuy was sinds 1746 predikant aan de Kaap en Vos' tijdgenoot Chr. Fleck was in 1779 al proponent en werd in 1780 predikant te Kaapstad). Het lijkt me, dat hij met dat ideaal zijn vrouw heeft overtuigd om zoveel jaren alleen te wachten. Zijn Merkwaardig Verhaal geeft daar dan ook een verwijzing voor. Toen hij afstudeerde was er echter geen vacante plaats aan de Kaap en Vos moest dus tevreden met het predikantschap in Nederland, in Woudenberg. Hij aanvaardde Gods weg met hem, schreef hij, maar dat vertrouwen werd niet gedeeld door zijn vrouw. Hij vond haar eens "in een wanhopenden toestand". "Mijne vrouw had zich sterk verbeeld, zekere belofte van God ontvangen te hebben, dat ik als leeraar naar de Kaap komen en God aldaar, door mij, groote en heerlijke dingen, tot heil van zijn Sion, verrichten zoude". Predikant aan de Kaap, in het Kaapse Sion. ${ }^{26}$ Vos en zijn vrouw dachten aan een succesvol predikantschap aan de Kaap, het bewerken van een opwekking in de kerk (dat was het gesprek en gebed van de kringen waar zij opgroeide. ${ }^{27}$ ). Niet aan een roeping voor de slaven, de gekleurden als Vos in die jaren inderdaad dacht aan zending onder slaven en gekleurde mensen, dan had hij natuurlijk aan de VOC kunnen vragen hem naar de Oost te zenden, naar een Maleis of Portugees sprekende gemeente, op Ceylin, in de Molukken. Dan had hij arme slaven en andere gekleurde mensen kunnen redden en troosten met het evangelie. ${ }^{28}$ Maar die vraag stelde hij Compagnie noch classis.

African Women's writing from 17th-Century Dutch to Contemporary Afrikaans (Leiden 2019).

25 Merkwaardig Verhaal, 68.

26 Sion was traditioneel de (confessionele) Gereformeerde Kerk; in sommige conventikels werd Sion verengd tot de groep van ware gelovigen en vervolgens in de geloofszending niet-confessioneel verbreed.

27 Vos, Merkwaardig verhaal, Brieven 2 en 3.

28 Zie voor de evangelisatie en zending onder de VOC: G.J. Schutte red., Het Indisch Sion. De Gereformeerde kerk onder de VOC (Hilversum 2002); H.E.Niemeijer, Calvinisme en koloniale stadscultuur Batavia 1619-1725 (diss. VUA 1996); Y. Soleiman, The Dutch Reformed Church in Late Eighteenth Century Java. An Eastern Adventure (diss. VUA 2011); H.E. Niemeijer, T. van den End eds, Bronnen betreffende Kerk en school in de gouvernementen Ambon, Ternate en Banda ten tijde van de VOC 1605-1791 (Den Haag 2015, 6 vol.). 
Recente auteurs als Huigen vinden Vos' verlangen, het evangelie onder de slaven te verbreiden, vanzelfsprekend: hij was zelf "zwart". Vos stelde zich zo immers zelf voor: "geboren van Christenouders, die van Europeesche en Aziatische voorouders afkomstig waren". ${ }^{29}$ Huigen leest in het Merkwaardig Verhaal dat Vos "van twee kanten, vaders- en moederszijde niet helemaal Europees was" en wijst dan op zijn grootmoeder aan moeders kant, Anna Groothenning van Bengalen en een grootmoeder aan vaders kant, Christina Baumann te Batavia, die gezien het feit dat in Batavia de meerderheid van de vrouw dat waren, een Euraziatische moet zijn geweest. Het Merkwaardig Verhaal is dus "het eerste boek dat werd geschreven door een zwarte schrijver in Zuid-Afrika". ${ }^{30}$ Overgrootmoeder Anna Groothenning (of Anna van Bengalen) was inderdaad "zwart", in de zin dat zij geen Europese maar een Aziatische vrouw was, verwant aan de mensen van Myanmar en Laos, ${ }^{31}$ geboren in 1676 (kreeg zij al direct de naam van Anna?) en aan de kust van Bengalen verkocht; door wie en wanneer is onbekend; het meest waarschijnlijk dat zij naar Batavia is gebracht en vandaar meegenomen door de VOC-schipper Cornelis Keeleman op de "Spiegel", die wist dat aan de Kaap altijd vraag naar slaven was. Hij arriveerde op 25 mei 1697 aan de Kaap en verkocht haar enkele dagen voor zijn vertrek voor de redelijk goede prijs van 54 Rijksdaalder aan de drankhandelaar Gerrit Hendrik Meijer. ${ }^{32} \mathrm{Zij}$ kreeg enkele malen een andere eigenaar, haar prijs steeg tot 70 Rijksdaalders (1702) en het jaar erop kocht de bakker H.K. Geringer haar. Anna had toen al een relatie met Geringers knecht/compagnon Christiaan Bok. Zo werd zij partner van een paar succesvolle bakkers; in 1709 stelde Geringer haar en haar kinderen in vrijheid. Haar kinderen waren als kinderen van Bok steeds gedoopt, nu werd ook zijzelf gedoopt na belijdenis (1 januari 1713) en op 5 februari 1713 trouwde zij officieel met Christiaan

29 Merkwaardig verhaal, 1.

30 Huigen, "Michiel Christiaan Vos", 204. Eep Franken, "Nederlandse romantiek in ZuidAfrika?", in Wandelaar onder de Palmen. Opstellen over postkoloniale literatuur en cultuur (Leiden 2004) 326-327 volgt Huigen.

31 Website Familysearch; ook (www.e-family.co.za: First Fifty Years - a project collating Cape of Cape of Good Hope records - Anna Groothenning van Bengale. : "mtDNA shows her to be a member of a haplogroup predominently originating in the region now politically defined als Myanmar and Laos."

32 A.J. Böeseken, Slaves and Free Blacks at the Cape 1658-1700 (Kaapstad 1977) 185 dateert de koop op 5.6.1698. Ik denk, dat dit jaartal een verschrijving is, Keeleman was 20 mei tot 17 juni 1697 aan de Kaap (website VOCopvarenden). 
Bok. ${ }^{33} \mathrm{Zij}$ overleefde Bock en Geringer en erfde beider nalatenschap, samen met de kinderen van Bok, zodoende elk kind een huis erfde. Anna Groothenning van Bengalen (overleden 1719) was dus een respectabele vrouw, haar kinderen trouwden met vrijburgers, Europese mannen en vrouwen, en zij waren zoals zoveel anderen met vergelijkbare herkomst gewoon lid van de Kaapse samenleving. ${ }^{34}$ Zoon Michiel Bok trouwde zelfs met een meisje uit de zeer vermogende familie Van der Poel, hun oudste dochter Johanna trouwde met J.H. Vos en werd de moeder van M.C. Vos. ${ }^{35}$

Grootmoeder Christina Baumann kan Aziatisch bloed hebben gehad, maar zeker is het niet; ze droeg de naam van haar vader, dus ze moet binnen een (formeel gesloten) huwelijk zijn geboren. Of Christina wel of niet een gemengde afkomst had was overigens feitelijk niet van veel belang; wat telde was dat zij vrij was en christen, Europese opvattingen en gedragingen vertoonde - niet kleur en afkomst. De wereld van de Compagnie was multiraciaal en multicultureel, in Batavia haast nog meer dan aan de Kaap, aziatische (en euraziatische) vrouwen als Anna Groothenning vond men tot de hoogste kringen van de VOC. ${ }^{36}$ Werd het Wilhelm Adriaan van der Stel aangewreven dat hij, net als M.C.Vos, een overgrootmoeder uit India had? M.C. Vos wist van zijn afstamming zoals heel veel andere Kapenaren zich van een dergelijke afstamming bewust waren. Het verhinderde hen (en ook Vos) niet, zich te ontplooien, en zelf slaven te bezitten. Niet de afstamming (en zorg om in onkunde levende verre familieleden), maar het christelijk geloof dreef Vos tot zijn zendingswerk, moeten we vaststellen.

Vos ontkende overzee nooit, dat hij van de Kaap kwam: hij was "Afrikaan" of "Afrikaner", zijn vrouw een "Afrikaansche". Het was geen verwijzing naar dat stukje niet-europese afkomst, maar dat hij geen Hollander of Utrechter was en dat Afrika, de Kaap, zijn thuis was. ${ }^{37}$ Misschien deed

33 First Fifty Years - project. Haar kinderen zijn opgegeven met verschillende vaders/ getuigen - ook niet-vaders konden getuigen.

34 C. de Wet, Die vryliede en vryswartes in die Kaapse nedersetting 1657-1707 (Kaapstad 1981); Anna J. Böeseken, Slaves and Free Blacks at the Cape 1658-1700 (Kaapstad 1977).

35 Karel Schoeman, Armosijn van die Kaap, die wêreld van 'n slawin, 1652-1733 (Kaapstad 2001), 664.

36 Hendrik E. Niemeijer, Batavia. Een koloniale samenleving in de 17de eeuw (Amsterdam 2005)

37 Merkwaardig Verhaal, 152, 67. 
hij het ook bewust, om een beetje bijzonder te zijn, bijna iets exotisch. Een gemeentelidmaat in zijn nieuwe gemeente Pijnacker (1789) ergerde zich aan Vos' oproep tot bekering. "Wat verbeeldt hij, die van half OostIndiën komt, zich, dat hij ons dwingen wilt?" Er zat in die dienst ook een dienstmeisje, die eens was gekomen "om een Afrikaan te zien". Toen Vos de kansel beklom, bekeek zij hem nauwkeurig en zei daarop tot haar tante naast haar: "Is het anders niet, hij ziet er even uit als een ander mensch" ${ }^{38}$

Langzaam aan verdween de Kaap bij het echtpaar Vos achter de horizon. Het ging goed met hen in Nederland, ook mevrouw (later terug aan de Kaap, drong zij na enige tijd aan opnieuw naar Nederland te gaan! $\left.{ }^{39}\right)$. Maar "toen ik mijne terugkeer naar de Kaap schier opgegeven had en te dien einde geene pogingen meer wilde aanwenden", maakte God een keer. Hij werd voor de Kaapse kerk aangesteld, een zeer invloedrijke, bevriende en geestverwante bewindhebber, Hendrik van Stralen, had de Deputaten laten meewerken. ${ }^{40}$

"Schier opgegeven" - "geene pogingen meer wilde aanwenden", "bij elke vacatuur, mij bij vernieuwing... had aangeboden": Vos gaf geen erg helder verslag van zijn streven naar de Kaap terug te gaan. ${ }^{41}$ Een lang onbekend gebleven archiefstuk in Hilversum (waar Vos in 1788 beroepen werd) geeft daar enig zicht op. Het betreft een overzicht van de handelingen van de Hilversumse kerkenraad rondom de vervulling van de vacature, veroorzaakt door het overlijden van de predikant, eind $1787 .{ }^{42} \mathrm{De}$ kerkenraad begon met het vragen aan het dorpsbestuur van instemming met het beroepsproces, dat moest immers de kosten dragen. Daarna reisden zij naar Utrecht en informeerden bij de hoogleraar theologie Gisbertus Bonnet ${ }^{43}$ welke geschikte kandidaten er beschikbaar waren: zij moesten orthodox zijn, enige ervaring hebben en zich als goede Orangisten hadden getoond tijdens de bijna burgeroorlog tussen Patriotten en Orangisten, in

38 Merkwaardig verhaal, 84; 98.

39 Merkwaardig verhaal, 137.

40 Merkwaardig verhaal, 104.

41 Merkwaardig verhaal, 103-104.

42 SAH, NHK inv. nr 75: Bartus Horst, Verslag; G.J. Schutte, "Het beroep van ds. M.C. Vos in 1788”, Hilversums Historisch Eijdschrift 40 (2020) 30-37.

43 A. van den End, Gisbertus Bonnet (Wageningen 1957). 
afgelopen oktober beëindigd door de inval van een Pruisisch leger dat de Patriotten had verjaagd en het stadhouderschap van Willem V hersteld. Het zal niet verbazen, dat Bonnet onder anderen met stip de naam van Vos noemde: hij had bijzondere attentie aan deze begaafde student geschonken. ${ }^{44}$ Anderhalve week later (24 februari 1788) zat de Hilversumse kerkenraad in Woudenberg onder het gehoor van ds.Vos; de week erna hoorden zij de dominee van De Bilt en daarop besloot men genoeg kandidaten te kennen om een groslijst van geschikte voorgangers voor Hilversum op te stellen (meestal liet men kandidaten ook een keertje preken in Hilversum). Elk van de zes kerkenraadsleden stelden drie namen voor, in een volgende vergadering werd de lijst ingekort tot 12 kandidaten en daaruit werd een viertal gekozen. In elke lijst stond de naam van Vos, ook onder het viertal, met de meeste stemmen. Daarop gaf het dorpsbestuur toestemming dat viertal voor te leggen voor een publieke stemming, waaraan het dorpsbestuur, de mannelijke lidmaten van de gemeente, en de kerkenraad deelnamen. In een officiële bijeenkomst van de gemeente, geopend met een gepaste preek van de consulent (de predikant van de buurgemeente Nieuw Loosdrecht), werd Vos met grote meerderheid van stemmen gekozen. De volgende dag bracht de schoolmeester van de dorpsschool de beroepsbrief aan Vos in Woudrichem, die dankbaar en vereerd was en enige dagen voor beraad vroeg. De dag erna reden consulent en kerkenraad naar Woudrichem, om hem te feliciteren en wijsheid toe te wensen om een goede beslissing te nemen. Vos antwoordde vroom en heel traditioneel tegelijk, dat hij hoopte "de wille des Heeren te mogen weten hoe te handelen" en hij zei ook te verwachten dat zijn gemeente er iets van zal zeggen. Maar daarop had hij nog een concrete vraag. De regering van Hilversum had naar aanleiding van de hoge kosten van het vorige beroep in 1776 een ook elders veelszins vigerend besluit genomen, dat wanneer een predikant binnen drie jaren weer vertrekt, Hilversum drie honderd gulden moest ontvangen van zijn nieuwe gemeente. Geldt die bepaling ook als hij (Vos) wordt geroepen door een buitenlandse kerk, en wel aan de Kaap de Goede Hoop? Als reden van die vraag vertelde hij "dat zijn Eerw. aldaar geboren is en ook begeerd hadde om als 't des Heeren wille was aldaar het Evangelie te verkondigen". ${ }^{45}$

44 Merkwaardig verhaal, 39-46.

45 Schutte, "Het beroep", 35. 
De kerkenraad gaf de vraag door aan de Hilversumse magistraat, en die was bereid hier een uitzondering te maken. Het heeft Vos overigens niet overgehaald om naar Hilversum te gaan, op 3 april stuurde hij "een expresse gezonden brief" dat hij de "belangens van Woudenberg" boven die van Hilversum liet prefereren. ${ }^{46}$ Hij bleef in Woudenberg tot oktober 1789, waarop hij naar Pijnacker ging en in november 1790 naar Woerden. Ik weet niet, of Vos in die laatste twee plaatsen ditzelfde voorbehoud heeft gesteld.

Er was een vacature in Kaapstad toen Vos arriveerde (maart 1794), maar conform de traditie werd daarvoor een plattelandsdominee bevorderd naar Kaapstad, in dit geval ds.J.A. Kuys, predikant in het Land van Waveren (Roodezand), en Vos kon hem daar opvolgen. ${ }^{47}$ Kuys was niet erg tevreden met de inwoners van het Land van Waveren, zij verzuimden de kerkdiensten, hoe vaak ook vermaand en bestraft. ${ }^{48} \mathrm{Op}$ de eerste kerkenraadsvergadering na zijn intree, 4 mei 1794, gaf Vos zijn programma: hij was van plan om de veertien dagen, als over de Heidelbergse Catechismus gepreekt werd, ook publiek te catechiseren, 's woensdags een huiscatechisatie geven en voor zover de omvang van de gemeente dit toestond huisbezoek doen. ${ }^{49}$ Kennelijk werd het goed ontvangen, want medio 1795 meldde Vos: "De gemijnte bloeid zeer, en is in het waarnemen van den openbaeren godsdient voorbeeldig; onderscheidene schijnen het waere zelfkennisse en tot een hartelijk vraagen na den Enigen Saligmaker in de beginselen gekomen sijn"; ook waren er 60 nieuwe lidmaten (van wie 9 met attest van elders). ${ }^{50} \mathrm{Het}$ kerkeraadsverslag van 4 januari 1798 rapporteerde de tien weken durende visitatiereis die Vos met ouderling S.W. du Toit in Graaf-Reinet (waar geen zelfstandige gemeente was) maakte. Zij waren "van die arme menschen onder in 't veld in liefde ontvangen en welgedaan" - Vos had er op het veld

46 Horst, 11. Vergelijk NHK 8, notulen 6.4.1788, ingekomen brief van M.C. Vos van 2 dezer: dat "zijn WelEdelens door sterke liefdesdrang van zijn tegenwoordige gemeinte en na bedaarde overweging van de zaken op de vriendelijkste wijze voor de beroepinge na Hilversum bedankte".

4734 Bouwstoffen II, 489.

48 Bouwstoffen I, 584.

49 Bouwstoffen II, 490.

50 Bouwstoffen I, 585. Het Doopboek van Tulbagh voor de jaren 1794 (63 jongens, 68 meisjes) en 1795, en de lijst van Belijdenissen 1794-1799 gaf geen namen van (ex-)slaven (GSSA). Van afzonderlijke beschrijving is me niets bekend. 
en bij huizen 25 keer gepreekt, 153 gedoopt, 22 lidmaten aangenomen. Zijn diensten op Roodezand waren in die tijd verzorgd door ds. Ballot, die met dankzegging 100 rijksdaalders kreeg. ${ }^{51}$ Dat zijn allemaal activiteiten, die vallen onder de gewone gemeentearbeid. Geen woord over zendingsarbeid onder slaven en heidenen.

Wat Vos in de kerkenraadsnotulen schreef, moest natuurlijk summier zijn en door alle kerkenraadsleden gedeeld worden. Toch is er een opmerkelijk verschil met wat Vos over dezelfde gebeurtenissen in zijn Merkwaardig verhaal schreef. Hoe verhoudt "de gemijnte bloeid zeer" in het kerkenraadsverslag met de vele bladzijden in het Merkwaardig verhaal over het verzet in de gemeente tegen Vos, begonnen met deze passage: "Aanstonds beduidde ik mijn nieuwe gemeente, dat ik ... tot hen gezonden was om aan alle creaturen, dus ook aan hunne dienstbaren en slaven het Evangelie te prediken ... Ik zou terstond beginnen, elken Zondag en Woensdagavond de Heidenen te onderwijzen ... Deze mijne aankondiging en uitnodiging verwekte geene kleine ontsteltenis in mijne gemeente, velen staken de hoofden bijelkander en fluisterden, na het eindigen van de godsdienstoefening elkander in: dat dit nooit goed gaan zoude". ${ }^{2}$

Een ander opmerkelijk verschil. Het kerkenraadsverslag geeft goede woorden over ds. Ballot als waarnemer. Maar in het Merkwaardig verhaal schreef Vos, dat hij na zijn terugkeer van die visitatiereis al spoedig vernam "zelfs aan de uitwendige vertooning, bijzonder van de jonge lieden, dat er een wolf onder de kudde geweest was, en aan dezelve een aantal gevaarlijke wonden had toegebracht". ${ }^{53}$ Prof. J. du Plessis voegde aan zijn uitgave van het Merkwaardig verhaal een aantekening toe, dat de jeugd van Roodezand in opstand kwam tegen de strenge piëtistische regels van Vos, die muziek, dans en vrolijkheid veroordeelden. Ballot had begrip voor het verzet van de jeugd. Ballot werd ook predikant van Roodezand toen Vos dat had verlaten, en was kennelijk ook de informant van de reiziger H. Lichtenstein, die Vos beschreef als "een ongeleerd mensch, zonder iets van de eigenlijke waardigheid eens predikanten, ... met een tjankerige,

51 Bouwstoffen II, 402.

52 Merkwaardig verhaal, 136.

53 Merkwaardig verhaal, 136. 
gemaakte nederigheid". ${ }^{44}$ Met andere woorden: dat oordeel "wolf" dateerde van twintig jaren na dato, gebaseerd op latere ervaringen, mogelijk regelrecht gericht tegen de woorden van Ballot aan Lichtenstein. Het is bepaald niet de enige passage in Vos' Merkwaardig Verhaal die niet de feitelijke geschiedenis weergeeft. Maar het is dan ook geen geschiedverhaal, maar een vrome opwekking.

\section{Bibliografie}

Böeseken, Anna J., Slaves and Free Blacks at the Cape 1658-1700. Kaapstad: Tafelberg 1977.

End, A. van den, Gisbertus Bonnet. Wageningen;:VADA 1957.

Franken, Eep. Nederlandse romantiek in Zuid-Afrika?, in Wandelaar onder de Palmen. Opstellen over postkoloniale literatuur en cultuur. Leiden 2004, 326-327.

Huigen, S., Michiel Christiaan Vos. De eerste zwarte schrijver in ZuidAfrika. Tydskrif

vir Nederlands en Afrikaans 1997, 203-209.

Lichtenstein, H., Reizen in het zuidelike gedeelte van Afrika in den jaren 1803-1806. Dordrecht: A. Blussé en Zoon 1813-1815.

Niemeijer, Hendrik E., Batavia. Een koloniale samenleving in de 17de eeuw. Amsterdam: Balans 2005.

Schoeman, Karel, Armosijn van die Kaap, die wêreld van 'n slawin, 1652-1733. Kaapstad: Human \& Rousseau 2001.

Schoeman, Karel, The early Mission /Die vroeë sending in Suid-Afrika. Pretoria: Protea 2007.

Schutte, G.J., Over bevindelijke vroomheid in de Kaapkolonie, NGTT 51(2010):131-142.

54 Merkwaardig verhaal. 258-262. Du Plessis citeerde Lichtenstein, maar geeft geen bronverwijzing; er verscheen een Nederlandse editie Reizen in het zuidelike gedeelte van Afrika in den jaren 1803-1806 (Dordrecht 1813-1815). 
Schutte, G.J. ed., Hendrik Swellengrebel in Afrika: Journalen van drie reizen in 1776-1777. Kaapstad: VRV/VRS 2018.

Spoelstra, C., Bouwstoffen voor de geschiedenis der NederduitschGereformeerde kerken in

Zuid-Afrika. Amsterdam-Kaapstad: Hollandsch-Afrikaansche Uitgevers Maatschappij v.h. Jacques Dusseaux \& Co. 1906-1907, 1936, 3 dln.

Toit, H.D.T.du, Michiel Christiaan Vos, Suid-Afrikaanse Biografiese Woordeboek II. Kaapstad: 1972, 844-846.

Vos, M.C., Merkwaardig verhaal aangaande het leven en de lotgevallen van Michiel Christiaan Vos, als predikant der Hervormde Christelijke Gemeente op onderscheidene plaatsen in Nederland, Afrika en Azië; van zijne Jeugd af tot den tijd van zijn Emeritusschap door hem zelven in den Jare 1819 briefsgewijze aan eenen vriend medegedeeld [Amsterdam: A.B. Saakes, 1824]. Nieuwe uitgave, van breedvoerige aanteekeningen voorzien door J. du Plessis, Uitgave der Bijbel-en Bid-Vereeniging. Kaapstad: Hollandsch-Afrikaansche Uitgevers Maatschappij v.h. Jacques Dusseau \& Co. 1911.

Vos, M.C., Ik zal u niet verlaten. Leven en werk van Michiel Christiaan Vos (1759-1826). Houten: Den Hertog 1999.

Wet, G.C. de, Die vryliede en vryswartes in die Kaapse nedersetting 1657-1707. Kaapstad:

Historiese Publikasie-vereniging 1988. 